\title{
Neoadjuvant therapy in pancreatic cancer: what is the true oncological benefit?
}

\author{
Lei Ren ${ }^{1,2} \cdot$ Carmen Mota Reyes $^{1} \cdot$ Helmut Friess ${ }^{1,3,4} \cdot$ Ihsan Ekin Demir ${ }^{1,3,4,5}$ (I)
}

Received: 19 July 2020 / Accepted: 22 July 2020 / Published online: 10 August 2020

(C) The Author(s) 2020

\begin{abstract}
Background Neoadjuvant therapies (neoTx) have revolutionized the treatment of borderline resectable (BR) and locally advanced (LA) pancreatic cancer (PCa) by significantly increasing the rate of R0 resections, which remains the only curative strategy for these patients. However, there is still room for improvement of neoTx in PCa.

Purpose Here, we aimed to critically analyze the benefits of neoTx in LA and BR PCa and its potential use on patients with resectable PCa. We also explored the feasibility of arterial resection (AR) to increase surgical radicality and the incorporation of immunotherapy to optimize neoadjuvant approaches in PCa.

Conclusion For early stage, i.e., resectable, $\mathrm{PCa}$, there is not enough scientific evidence for routinely recommending neoTx. For LA and BR PCa, optimization of neoadjuvant therapy necessitates more sophisticated complex surgical resections, machine learning and radiomic approaches, integration of immunotherapy due to the high antigen load, standardized histopathological assessment, and improved multidisciplinary communication.
\end{abstract}

Keywords Pancreatic cancer $\cdot$ Neoadjuvant therapy $\cdot$ Arterial resection $\cdot$ Immunotherapy

\section{Introduction}

The introduction of neoTx has led to a remarkable increase in the rate of surgical resections in PCa patients with LA or BR tumors, which were initially deemed inoperable at the time of diagnosis. However, two-thirds of these patients will develop local recurrences shortly after the operation [1]. In order to

Lei Ren and Carmen Mota Reyes contributed equally to this work.

Ihsan Ekin Demir

ekin.demir@tum.de

1 Department of Surgery, Klinikum rechts der Isar, School of Medicine, Technical University of Munich, Ismaninger Str. 22, D-81675 Munich, Germany

2 Department of General Surgery (Gastrointestinal Surgery), The Affiliated Hospital of Southwest Medical University, Luzhou, Sichuan, China

3 German Cancer Consortium (DKTK), Partner Site Munich, Munich, Germany

4 CRC 1321 Modelling and Targeting Pancreatic Cancer, Munich, Germany

5 Department of General Surgery, HPB Unit, School of Medicine, Acibadem Mehmet Ali Aydinlar University, Istanbul, Turkey avoid disease relapse, surgeons have struggle to find ways to maximize $\mathrm{R} 0$ resections that still remain the only curative alternative for long-term survival in PCa. Although the first attempts of arterial resections (AR) in advanced tumors did not show the expected success, improved perioperative management and the integration of neoTx into multimodal therapy approaches have resulted in significantly reduced perioperative mortality and have proven the safety and feasibility of these radical approaches. Although neoTx is the standard of care for BR and LA tumors, its application on upfront resectable patients in order to downstage tumors and to increase surgical radicality is still subject of investigation. Furthermore, the introduction of immunotherapy to reactivate the pancreatic tumor microenvironment (TME) specially in neadjuvant settings constitutes a promising strategy for future multimodality PCa treatments (Fig. 1) [2, 3].

\section{NeoTx in borderline resectable and locally advanced PCa}

Upfront surgery in BR and LA tumors has not elicited the expected survival benefit and is associated with high morbidity, low R0 resection rat, and high early-systemic recurrences 
Fig. 1 The evolving arms of a pleiotropic neoadjuvant therapy (neoTx) for locally advanced pancreatic cancer (PCa). We envision that the survival benefit through neoTx in locally advanced or borderline resectable $\mathrm{PCa}$ can be further improved via (1) more sophisticated approaches for complex surgical resections, (2) increased integration of radiomic approaches to staging and restaging after neoTx, (3) testing of immunotherapy in the neoadjuvant setting due to the relatively higher antigen load of the tumor, (4) worldwide standardization of the histopathological assessment, and (5) improved communication between all disciplines

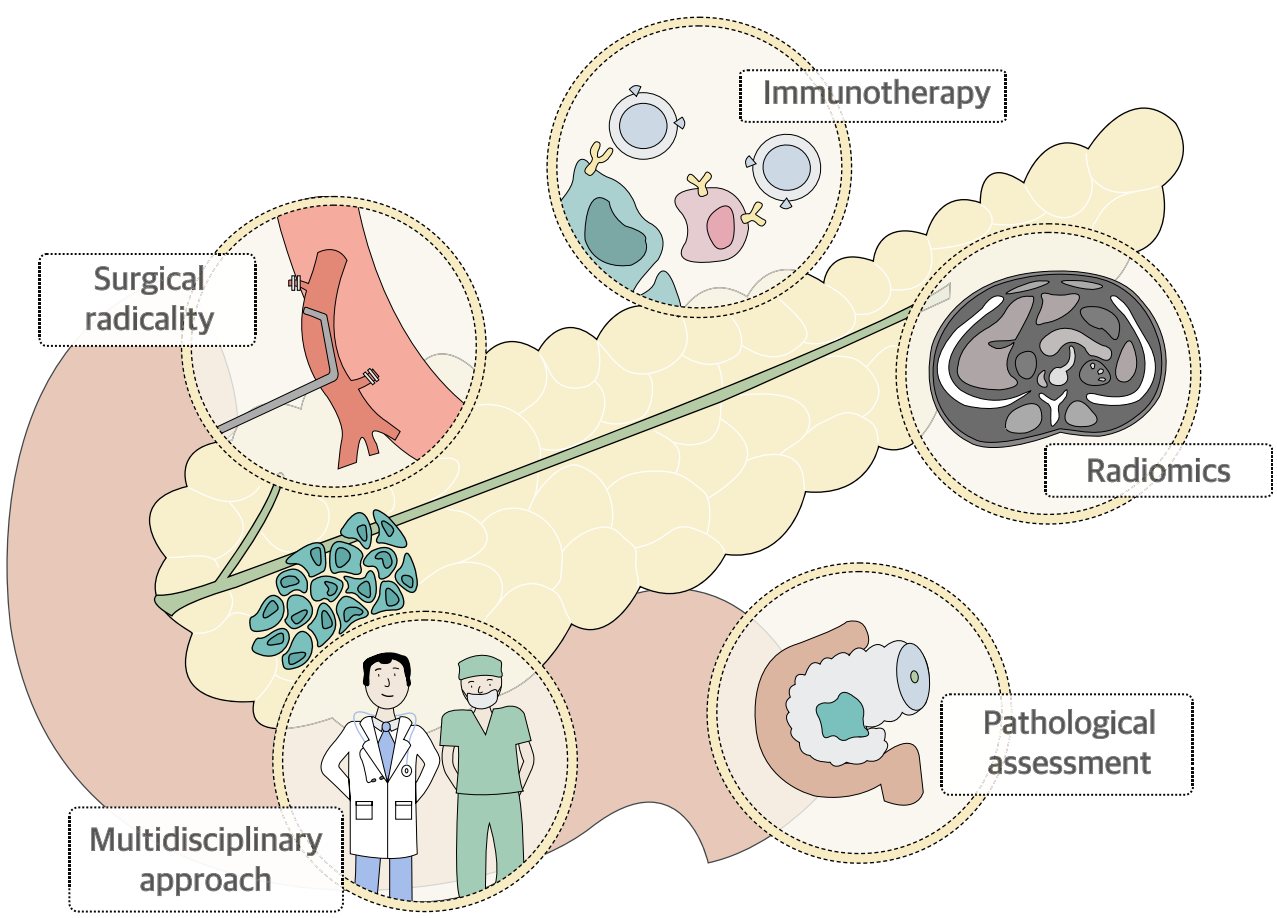

[4]. The introduction of neoadjuvant approaches enabling the tumor downstaging has led to successful surgical resection in up to $60 \%$ of these patients [5]. However, neoTx not only decreases tumor size and facilitates surgical resection but also enables the selection of patients with a favorable tumor biology, who will benefit from radical resections [6]. A multicenter phase III randomized controlled trial (RCT) validated the use of neoTx in BR PCa patients. The initial analysis showed that neoTx resulted in increased $\mathrm{R} 0$ resection rates and prolonged disease-free survival (DFS) [7]. However, the final results showed that the neoTx protocol (preoperative gemcitabine-based chemotherapy combined with $15 \times$ 2.4 Gy radiotherapy) did not improve the overall survival [7]. After neoTx, PCa patients with LA tumors demonstrate favorable histopathological features with higher R0 resection rates and decreased frequency of lymph node metastasis and perineural and lymphatic vessel invasion [8]. These encouraging results have led to an increasing number of neoadjuvantly treated patients; however, not all of these patients ultimately undergo surgical exploration. Mellon et al. reported that 46 of 110 patients with BR PCa became unresectable due to local/ distant progression or due to poor performance status that precluded resection after neoTx [9]. Importantly, therapeutic response to neoTx is not reliably reflected by the current imaging techniques. This highlights the need for multidisciplinary communications between surgeons and oncologists to ensure an unbiased selection of patients for surgical exploration and an optimized patient management in PCa.

Conventional computed tomography (CT), the most commonly used imaging modality for the initial determination of tumor stage and resectability of PCa, has striking limitations in the evaluation of vessel involvement after neoTx [10]. The recent introduction of whole-tumor radiomic analysis has opened a range of possibilities to assess therapy response and resectability in $\mathrm{PCa}$ in a quantitative and non-invasive manner. A supervised machine learning algorithm from diffusion-weighted magnetic resonance imaging allowed overall survival (OS) prediction with a high diagnostic accuracy as well as histopathological sub-stratification of PCa patients [11]. Recent reports also pointed out that the combination of radiomic features such as reduced tumor stiffness in endosonographic elastography or reduced intensity on PET$\mathrm{CT}$ is able to assess therapy response in PCa after neoTx [12]. While still in need of validation studies, the large-scale implementation of such tools has the potential to revolutionize image interterpretation and individualized patient care [11].

\section{NeoTx in resectable PCa: illusion versus reality}

Although upfront surgery followed by adjuvant chemotherapy is still the recommendation for resectable $\mathrm{PCa}$, this treatment fails to discriminate patients with undetected metastatic dissemination or aggressive tumor biology that may not benefit from surgical resection [13]. Furthermore, due to the high postoperative morbidity associated with pancreatic resections, up to $30 \%$ fail to receive or complete adjuvant chemotherapy [14]. The success of neoTx in BR/LA tumors has raised the question whether neoTx can improve prognosis in resectable 
patients, and clinical trials addressing to this matter are increasingly emerging.

The potential risk for patients with resectable $\mathrm{PCa}$ to develop local or distant tumor progression during neoTx, which might not have occurred in the setting of upfront resection, has been a recurrent argument against the use of neoTx in resectable tumors. The therapeutic paradigm of $\mathrm{PCa}$ is constantly evolving, and the focus has now turned toward the ability of the surgeon to remove the tumor radically. In this regard, neoTx may reduce surgical complexity by reducing the tumor bulk, the proportion of viable tumor cells, and the involvement of nearby vascular structures, resulting in an increased $\mathrm{R} 0$ resection rate [15].

Two early studies comparing the efficacy of gemcitabinebased neoTx with upfront surgery for resectable PCa determined its safety and feasibility but were terminated early due to slow recruitment and did not achieve statistically significant results $[6,16,17]$. Accordingly, two RCTs reported recently that neoTx is safe and effective without increased risk of surgical complications and was associated with favorable R0 resection rates in patients with resectable $\mathrm{PCa}$ [18]. In a large retrospective study, Mockdad et al. described prolonged survival in neoadjuvant-treated patients with early-stage $\mathrm{PCa}$ compared with upfront resected patients and thus provided further support for the use of neoTx as a patient selection tool in the management of resectable PCa [14]. Moreover, grade 3/ 4 toxicity in resectable PCa patients treated with neoTx was lower than in patients with BR/LA disease $[19,20]$. In contrast, the recently published PREOPANC trial failed to any benefit in overall survival of patients with borderline or upfront resectable $\mathrm{PCa}$ (16.0 months with preoperative chemoradiotherapy versus 14.3 months with upfront surgery $P=.096)$. Therefore, for early-stage, i.e., resectable, $\mathrm{PCa}$, there is not enough scientific evidence for routinely recommending neoTx [7]. NeoTx in resectable PCa remains area of controversy and awaits the results of ongoing RCTs [21].

\section{Radical resection in PCa: "the holy grail"}

Curative R0 resection remains the only chance for long-term survival in PCa $[22,23]$; however, approximately half of the resections are microscopically incomplete and two-thirds of initially R0-diagnosed patients will develop local recurrence [24]. Despite the prognostic relevance of the pathological resection rate, a standard definition for $\mathrm{R} 0$ resection is still lacking, which leads to high variability on R0 resection rates that range between $15 \%$ and $92 \%[1,24-26]$. After the introduction of a standardized pathology protocol consisting of axial slicing technique, multicolor margin staining and extended sampling, and a circumferential resection margin $(\mathrm{CRM})>$ $1 \mathrm{~mm}$, the R1 rate significantly increased from 14 to $76 \%$ in a retrospective study carried out by Esposito et al. [27, 28].
These observations indicate that resection margin involvement is a common finding in PCa which is often underestimated due to the lack of a standardized pathological examination of all relevant margins [28] and insinuated the need to increase surgical radicality in other to obtain wider resection margins and higher R0 rates. In line with these results, a retrospective study with 360 patients revealed similar local recurrence rates of R0- and R1-staged PCa patients suggesting the widespread presence of undiagnosed microscopic residual disease. Further intercontinental discrepancy is reported on the definition of R0 status, which is $0-\mathrm{mm}$ tumor distance from resection margin in the USA and $>1 \mathrm{~mm}$ in Europe and Australia [1, 24, 27, 29, 30]. In our recent metaanalysis assessing the importance of the resection status in $\mathrm{PCa}$, we demonstrated that even with standardized pathology protocols, resection margin's prognostic validity may be primarily confined to pancreatic head tumors [24].

Pancreatic surgeons are continuously developing new strategies to increase surgical radicality and improve $\mathrm{R} 0$ resection rates [4]. The feasibility of portomesenteric venous resection has been widely demonstrated. In contrast, extended arterial involvement remains a controversial issue in the management of PCa. Although tumor encasement of the superior mesenteric artery, common hepatic artery, or celiac artery defines local irresectability according to current guidelines, advances in the field of pancreatic surgery have turned the focus on redefining strategies that allow more radical approaches involving the resection and reconstruction of major peripancreatic arteries, to achieve R0 resection in patients without distant metastasis [4, 31].

In the first meta-analysis evaluating $\mathrm{AR}$ in patients undergoing pancreatectomy for PCa, AR was discouraged as standard of care and was associated with remarkably higher perioperative morbidity $(\mathrm{OR}=2.17)$ and mortality $(\mathrm{OR}=5.04)$ and poor survival $(\mathrm{OR}=0.50)$ [4]. Conversely, in a recent study, Del Chiaro et al. demonstrated the feasibility and safety of AR in pancreatectomy, which was accompanied by increased survival compared with palliative procedures and showed no difference in postoperative mortality and morbidity, even though it was associated with longer operation time and higher blood loss [31, 32]. Consistent with these results, Sonohara et al. demonstrated that PCa patients with AR had marginally higher recurrence-free survival and longer overall survival without a significant increase in the incidence of severe postoperative complications [33]. Current studies evaluating celiac artery resection also showed that these procedures can be performed safely and with an encouraging median survival [32, 34]. Further analyses suggested the improvement to be a consequence of newly developed and more effective chemotherapeutical regimens used in neoadjuvant settings. The increasing use of neoTx has notably increased the rate of R0 resections in patients with initially suspected arterial infiltration [35] and has led to significantly higher survival 


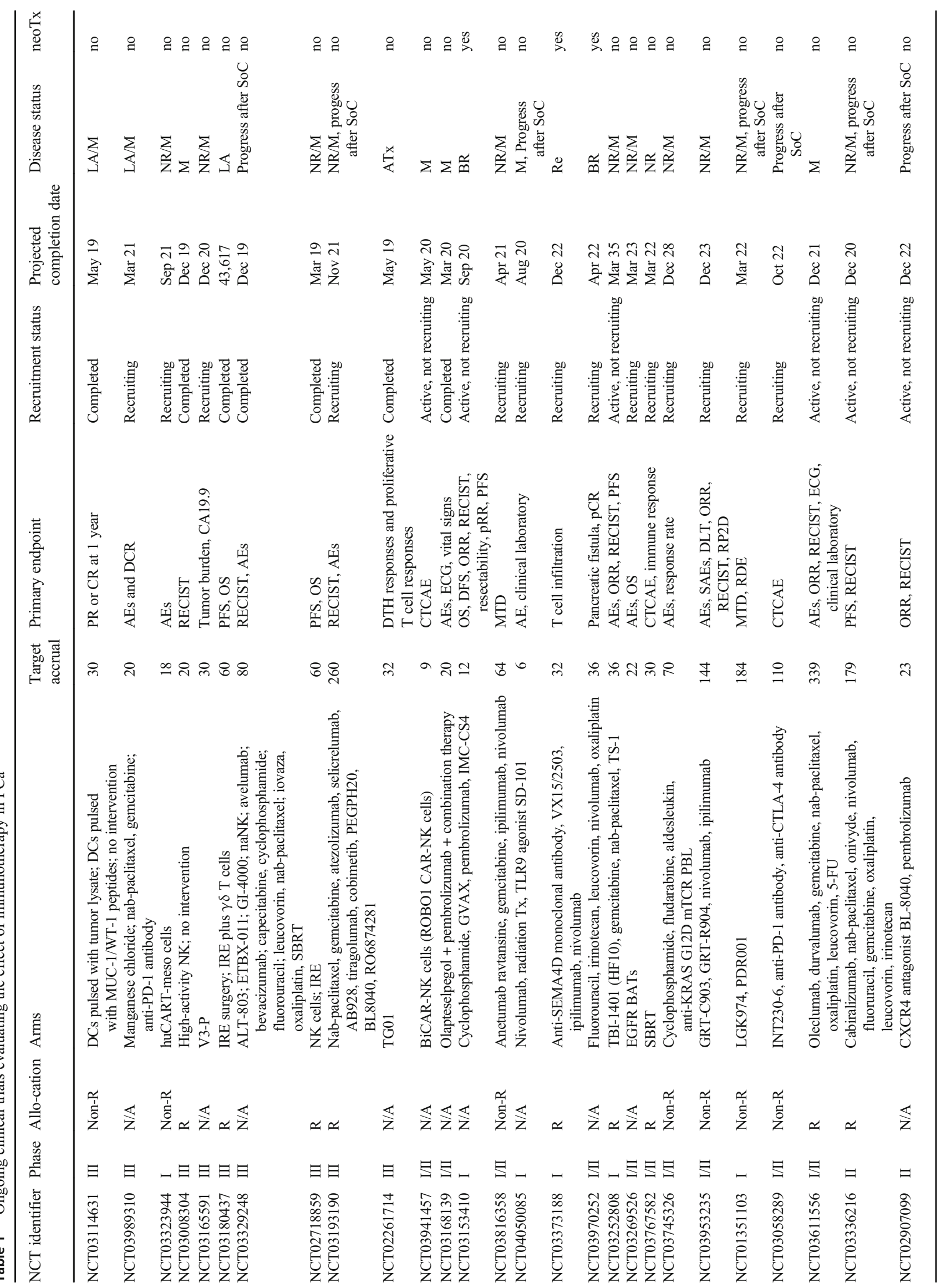




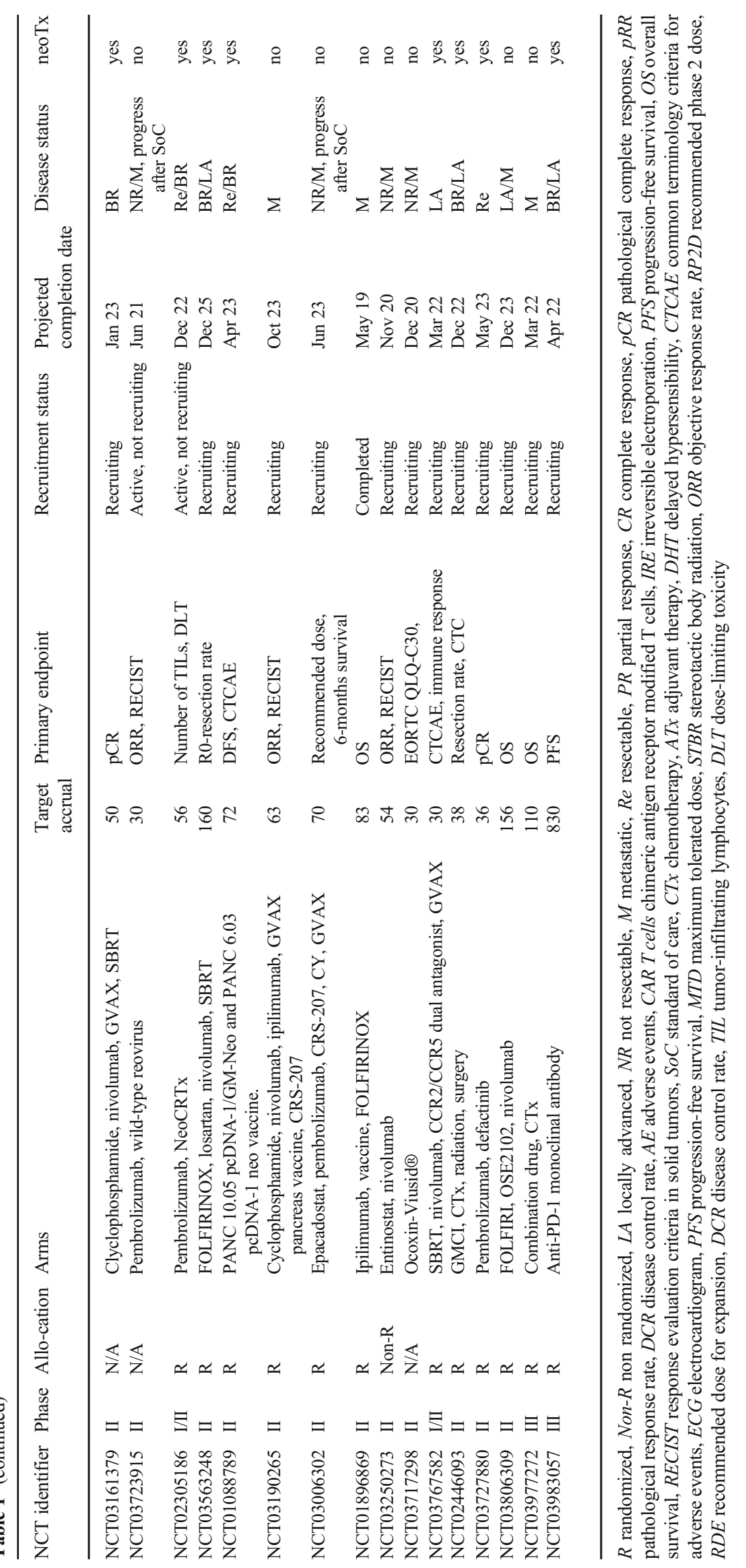


rates $(78.8 \%)$ compared with patients who underwent upfront surgery $(26.7 \%)$ [36]. In line with these results, Bachellier et al. reported remarkably prolonged survival in neoadjuvantly treated patients (23 months) compared with upfront resected PCa patients (13.7 months) after extended pancreatectomies involving AR [37]. Therefore, neoTx appears to provide an additional benefit to AR in patients with BR and LA PCa undergoing extended pancreatectomy by decreasing tumor burden and arterial invasion [33, 38]. In the case of adequate therapeutic response and good performance status, resectability should be re-assesed via surgical exploration, as crosssectional images often fail to identify the extent of the remaining viable tumor. Combining AR with pancreatectomy in these cases increases the feasibility of $\mathrm{R} 0$ resection, which is still the only option to achieve long-term survival [39]. Here, neoTx should be performed rather than upfront surgery. Clinical trials analyzing the superiority of combined chemotherapeutical regimes and radical surgical resections are still needed and ongoing [4, 40-42].

\section{Immunotherapy as a novel neoadjuvant approach in $\mathrm{PCa}$}

Cancer immunotherapy has demonstrated remarkable therapeutic efficacy in many solid malignancies [43]. Due to low tumor mutational burden and the presence of a highly immunosuppressive TME, immunotherapies have consistently failed to elicit the expected outcomes in PCa [44]. This limitation may be circumvented by the application of immunotherapy in a neoadjuvant setting, with the primary tumor serving as an antigen source for in situ $\mathrm{T}$ cell priming that may unleash a more potent antitumoral immune response compared with adjuvant approaches [45]. Current neoTx in PCa mostly relies on classical chemotherapy regimens such as FOLFIRINOX and does not make use of immune-based and molecular-targeted therapies. Surprisingly, we observed an immunological shift toward more cytotoxic inflammation in the TME of PCa after conventional neoTx. This was mainly due to the depletion of immunosuppressive cells like regulatory T cells (Treg cells) [46] and myeloid-derived suppressor cells (MDSCs) $[45,47]$. These results suggested that neoTx is able to prime the TME and potentiate the effect of immunotherapy by boosting the local antitumor immune response in $\mathrm{PCa}$.

Ongoing trials on $\mathrm{PCa}$ are now focusing on combinatorial approaches exploiting the ability of cancer vaccines to promote $\mathrm{T}$ cell recruitment followed by the subsequent activation of cytotoxic cells by checkpoint inhibitors (ICIs) or immunomodulatory agents [48]. The inhibition of T cell checkpoints such as T lymphocyte protein 4 (CTLA4) and programmed cell death protein 1 (PD-1) has shown enormous promise in a number of cancer types $[49,50]$ by unleashing tumor-specific cytotoxic $\mathrm{T}$ cells that already reside in TME before treatment
[51]. So far, none of these antagonists has proven effective in $\mathrm{PCa}$ [48]. However, the combination of a CD40 agonist with nab-paclitaxel plus gemcitabine resulted in partial response in 4 of 21 patients with $\mathrm{PCa}$, and a clinical trial for its use as a neoadjuvant is underway (NCT02588443). Adoptive immunotherapy involves the injection of tumor reactive immune cells into patients and has increasingly gained attention over the past years. Although the first clinical trials with chimeric antigen receptor (CAR) $\mathrm{T}$ cells or tumor-pulsed dendritic cells in advanced PCa have shown promise [48], adoptive approaches have yet not been tested in neoadjuvant settings in PCa. The number of clinical trials evaluating the use of neoadjuvant immunotherapy is limited compared with its use within palliative approaches (Table 1).

In low mutational tumors such as PCa, neoTx may be particularly beneficial to potentiate the antitumor immune response compared with adjuvant approaches, as the tumor epithelium itself remains an essential source for the release of tumor antigens and cross-priming of tumor-directed $\mathrm{T}$ cell responses. This important reservoir for induction of tumordirected immune responses is no longer available after tumor resection [52]. Liu et al. administrated various combination immunotherapies in either neoadjuvant or adjuvant setting and discovered that regardless of the type of immunotherapy used, neoadjuvant approaches were superior to adjuvant treatments in primary breast tumors [53]. In line with these observations, Brooks et al. demonstrated that only the combination of neoadjuvantly applied gemcitabine and a PD-1 inhibitor, but not adjuvant treatment, effectively suppressed local tumor recurrence and improved survival in a transgenic mouse model of PCa [52].

\section{Conclusion}

NeoTx leads to an immunologic shift toward a more effective antitumor immune response in the pancreatic TME, which recently provided impetus for studying the possibility of combining neoTx with immunotherapy in patients with PCa. Furthermore, neoTx leads to increased $\mathrm{R} 0$ resection rates and reduces the complexity of pancreatic surgical resections in LA/BR PCa patients. After neoTx, the postoperative morbidity associated with AR in pancreatectomy was similar to less radical approaches, leading the way to more sophisticated and radical surgical strategies in PCa. However, for resectable $\mathrm{PCa}$, the overall survival benefit through neoTx does not exist in a convincing extent. Optimal drug regimens, timing of surgery with regard to therapy, and the role of additional immunotherapy still need to be defined. Balancing the optimal therapy for PCa will be complex and will require correct patient stratification, the use of combination strategies, and improved interdisciplinary cooperation. 
Funding information Open Access funding provided by Projekt DEAL. IED was funded by the Deutsche Forschungsgemeinschaft (DFG, German Research Foundation)—-project ID 329628492-SFB 1321.

\section{Compliance with ethical standards}

Conflict of interest The authors declare that they have no conflict of interest.

Ethical approval This article does not contain any studies with human participants performed by any of the authors. The article does not contain any animal experiments.

Open Access This article is licensed under a Creative Commons Attribution 4.0 International License, which permits use, sharing, adaptation, distribution and reproduction in any medium or format, as long as you give appropriate credit to the original author(s) and the source, provide a link to the Creative Commons licence, and indicate if changes were made. The images or other third party material in this article are included in the article's Creative Commons licence, unless indicated otherwise in a credit line to the material. If material is not included in the article's Creative Commons licence and your intended use is not permitted by statutory regulation or exceeds the permitted use, you will need to obtain permission directly from the copyright holder. To view a copy of this licence, visit http://creativecommons.org/licenses/by/4.0/.

\section{References}

1. Schlitter AM, Esposito I (2010) Definition of microscopic tumor clearance (r0) in pancreatic cancer resections. Cancers (Basel) 2(4): 2001-2010. https://doi.org/10.3390/cancers2042001

2. Tempero MA, Malafa MP, Chiorean EG, Czito B, Scaife C, Narang AK, Fountzilas C, Wolpin BM, Al-Hawary M, Asbun H, Behrman SW, Benson AB, Binder E, Cardin DB, Cha C, Chung V, Dillhoff M, Dotan E, Ferrone CR, Fisher G, Hardacre J, Hawkins WG, Ko AH, LoConte N, Lowy AM, Moravek C, Nakakura EK, O'Reilly EM, Obando J, Reddy S, Thayer S, Wolff RA, Burns JL, Zuccarino-Catania G (2019) Pancreatic adenocarcinoma, Version 1.2019. J Natl Compr Cancer Netw 17(3):202-210. https://doi.org/ 10.6004/jncen.2019.0014

3. Li D, Xie K, Wolff R, Abbruzzese JL (2004) Pancreatic cancer. Lancet 363(9414):1049-1057. https://doi.org/10.1016/S01406736(04)15841-8

4. Mollberg N, Rahbari NN, Koch M, Hartwig W, Hoeger Y, Buchler MW, Weitz J (2011) Arterial resection during pancreatectomy for pancreatic cancer: a systematic review and meta-analysis. Ann Surg 254(6):882-893. https://doi.org/10.1097/SLA.0b013e31823ac299

5. Hackert T, Sachsenmaier M, Hinz U, Schneider L, Michalski CW, Springfeld C, Strobel O, Jager D, Ulrich A, Buchler MW (2016) Locally advanced pancreatic cancer: meoadjuvant therapy with folfirinox results in resectability in $60 \%$ of the patients. Ann Surg 264(3):457-463. https://doi.org/10.1097/SLA.0000000000001850

6. Oba A, Ho F, Bao QR, Al-Musawi MH, Schulick RD, Del Chiaro $M(2020)$ Neoadjuvant treatment in pancreatic cancer. Front Oncol 10:245. https://doi.org/10.3389/fonc.2020.00245

7. Versteijne E, Suker M, Groothuis K, Akkermans-Vogelaar JM, Besselink MG, Bonsing BA, Buijsen J, Busch OR, Creemers GM, van Dam RM, Eskens F, Festen S, de Groot JWB, Groot Koerkamp B, de Hingh IH, Homs MYV, van Hooft JE, Kerver ED, Luelmo SAC, Neelis KJ, Nuyttens J, Paardekooper G, Patijn GA, van der Sangen MJC, de Vos-Geelen J, Wilmink JW,
Zwinderman AH, Punt CJ, van Eijck CH, van Tienhoven G, Dutch Pancreatic Cancer G (2020) Preoperative chemoradiotherapy versus immediate surgery for resectable and borderline resectable pancreatic cancer: results of the Dutch randomized phase III PREOPANC trial. J Clin Oncol 38:JCO1902274-JCO1901773. https://doi.org/10.1200/JCO.19.02274

8. Schorn S, Demir IE, Reyes CM, Saricaoglu C, Samm N, Schirren R, Tieftrunk E, Hartmann D, Friess H, Ceyhan GO (2017) The impact of neoadjuvant therapy on the histopathological features of pancreatic ductal adenocarcinoma - a systematic review and metaanalysis. Cancer Treat Rev 55:96-106. https://doi.org/10.1016/j. ctrv.2017.03.003

9. Mellon EA, Hoffe SE, Springett GM, Frakes JM, Strom TJ, Hodul PJ, Malafa MP, Chuong MD, Shridhar R (2015) Long-term outcomes of induction chemotherapy and neoadjuvant stereotactic body radiotherapy for borderline resectable and locally advanced pancreatic adenocarcinoma. Acta Oncol 54(7):979-985. https://doi. org/10.3109/0284186X.2015.1004367

10. Zins M, Matos C, Cassinotto C (2018) Pancreatic adenocarcinoma staging in the era of preoperative chemotherapy and radiation therapy. Radiology 287(2):374-390. https://doi.org/10.1148/radiol. 2018171670

11. Kaissis G, Ziegelmayer S, Lohofer F, Algul H, Eiber M, Weichert W, Schmid R, Friess H, Rummeny E, Ankerst D, Siveke J, Braren $\mathrm{R}$ (2019) A machine learning model for the prediction of survival and tumor subtype in pancreatic ductal adenocarcinoma from preoperative diffusion-weighted imaging. Eur Radiol Exp 3(1):41. https://doi.org/10.1186/s41747-019-0119-0

12. Tanaka M, Heckler M, Mihaljevic AL, Sun H, Klaiber U, Heger U, Buchler MW, Hackert T (2019) CT response of primary tumor and CA19-9 predict resectability of metastasized pancreatic cancer after FOLFIRINOX. Eur J Surg Oncol 45(8):1453-1459. https://doi.org/ 10.1016/j.ejso.2019.03.039

13. Seufferlein T, Ettrich TJ (2019) Treatment of pancreatic cancerneoadjuvant treatment in resectable pancreatic cancer (PDAC). Transl Gastroenterol Hepatol 4:21. https://doi.org/10.21037/tgh. 2019.03.05

14. Mokdad AA, Minter RM, Zhu H, Augustine MM, Porembka MR, Wang SC, Yopp AC, Mansour JC, Choti MA, Polanco PM (2017) Neoadjuvant therapy followed by resection versus upfront resection for resectable pancreatic cancer: a propensity score matched analysis. J Clin Oncol 35(5):515-522. https://doi.org/10.1200/JCO. 2016.68.5081

15. Takahashi H, Ohigashi H, Gotoh $\mathrm{K}$, Marubashi S, Yamada T, Murata M, Ioka T, Uehara H, Yano M, Ishikawa O (2013) Preoperative gemcitabine-based chemoradiation therapy for resectable and borderline resectable pancreatic cancer. Ann Surg 258(6): 1040-1050. https://doi.org/10.1097/SLA.0b013e31829b3ce4

16. Golcher H, Brunner TB, Witzigmann H, Marti L, Bechstein WO, Bruns C, Jungnickel H, Schreiber S, Grabenbauer GG, Meyer T, Merkel S, Fietkau R, Hohenberger W (2015) Neoadjuvant chemoradiation therapy with gemcitabine/cisplatin and surgery versus immediate surgery in resectable pancreatic cancer: results of the first prospective randomized phase II trial. Strahlenther Onkol 191(1):716

17. Casadei R, Di Marco M, Ricci C, Santini D, Serra C, Calculli L, D'Ambra M, Guido A, Morselli-Labate AM, Minni F (2015) Neoadjuvant chemoradiotherapy and surgery versus surgery alone in resectable pancreatic cancer: a single-center prospective, randomized, controlled trial which failed to achieve accrual targets. J Gastrointest Surg 19(10):1802-1812. https://doi.org/10.1007/ s11605-015-2890-4

18. Reni M, Balzano G, Zanon S, Zerbi A, Rimassa L, Castoldi R, Pinelli D, Mosconi S, Doglioni C, Chiaravalli M, Pircher C, Arcidiacono PG, Torri V, Maggiora P, Ceraulo D, Falconi M, Gianni L (2018) Safety and efficacy of preoperative or 
postoperative chemotherapy for resectable pancreatic adenocarcinoma (PACT-15): a randomised, open-label, phase 2-3 trial. Lancet Gastroenterol Hepatol 3(6):413-423. https://doi.org/10.1016/ S2468-1253(18)30081-5

19. Assifi MM, Lu X, Eibl G, Reber HA, Li G, Hines OJ (2011) Neoadjuvant therapy in pancreatic adenocarcinoma: a metaanalysis of phase II trials. Surgery 150(3):466-473. https://doi. org/10.1016/j.surg.2011.07.006

20. Gillen S, Schuster T, Meyer Zum Buschenfelde C, Friess H, Kleeff J (2010) Preoperative/neoadjuvant therapy in pancreatic cancer: a systematic review and meta-analysis of response and resection percentages. PLoS Med 7(4):e1000267

21. Bradley A, Van Der Meer R (2019) Upfront surgery versus neoadjuvant therapy for resectable pancreatic cancer: systematic review and Bayesian network meta-analysis. Sci Rep 9(1):4354. https:// doi.org/10.1038/s41598-019-40951-6

22. Michalski CW, Weitz J, Buchler MW (2007) Surgery insight: surgical management of pancreatic cancer. Nat Clin Pract Oncol 4(9): 526-535. https://doi.org/10.1038/ncponc0925

23. Hartwig W, Gluth A, Hinz U, Koliogiannis D, Strobel O, Hackert T, Werner J, Buchler MW (2016) Outcomes after extended pancreatectomy in patients with borderline resectable and locally advanced pancreatic cancer. Br J Surg 103(12):1683-1694. https:// doi.org/10.1002/bjs.10221

24. Demir IE, Jager C, Schlitter AM, Konukiewitz B, Stecher L, Schorn S, Tieftrunk E, Scheufele F, Calavrezos L, Schirren R, Esposito I, Weichert W, Friess H, Ceyhan GO (2018) R0 versus R1 resection matters after pancreaticoduodenectomy, and less after distal or total pancreatectomy for pancreatic cancer. Ann Surg 268(6):1058-1068. https://doi.org/10.1097/ SLA.0000000000002345

25. Kommalapati A, Tella SH, Goyal G, Ma WW, Mahipal A (2018) Contemporary management of localized resectable pancreatic cancer. Cancers (Basel) 10(1). https://doi.org/10.3390/ cancers 10010024

26. Chatelain D, Flejou JF (2002) Pancreatectomy for adenocarcinoma: prognostic factors, recommendations for pathological reports. Ann Pathol 22(5):422-431

27. Esposito I, Kleeff J, Bergmann F, Reiser C, Herpel E, Friess H, Schirmacher P, Buchler MW (2008) Most pancreatic cancer resections are R1 resections. Ann Surg Oncol 15(6):1651-1660. https:// doi.org/10.1245/s10434-008-9839-8

28. Verbeke CS, Menon KV (2009) Redefining resection margin status in pancreatic cancer. HPB (Oxford) 11(4):282-289. https://doi.org/ 10.1111/j.1477-2574.2009.00055.x

29. Markov P, Satoi S, Kon M (2016) Redefining the R1 resection in patients with pancreatic ductal adenocarcinoma. J Hepatobiliary Pancreat Sci 23(9):523-532. https://doi.org/10.1002/jhbp.374

30. Jamieson NB, Foulis AK, Oien KA, Going JJ, Glen P, Dickson EJ, Imrie CW, McKay CJ, Carter R (2010) Positive mobilization margins alone do not influence survival following pancreaticoduodenectomy for pancreatic ductal adenocarcinoma. Ann Surg 251(6): 1003-1010. https://doi.org/10.1097/SLA. 0b013e3181d77369

31. Del Chiaro M, Rangelova E, Halimi A, Ateeb Z, Scandavini C, Valente R, Segersvard R, Arnelo U, Verbeke CS (2019) Pancreatectomy with arterial resection is superior to palliation in patients with borderline resectable or locally advanced pancreatic cancer. HPB (Oxford) 21(2):219-225. https://doi.org/10.1016/j. hpb.2018.07.017

32. Zhou YM, Zhang XF, Li XD, Liu XB, Wu LP, Li B (2014) Distal pancreatectomy with en bloc celiac axis resection for pancreatic body-tail cancer: is it justified? Med Sci Monit 20:1-5. https://doi. org/10.12659/MSM.889847

33. Sonohara F, Yamada S, Takami H, Hayashi M, Kanda M, Tanaka C, Kobayashi D, Nakayama G, Koike M, Fujiwara M, Fujii T,
Kodera Y (2019) Novel implications of combined arterial resection for locally advanced pancreatic cancer in the era of newer chemoregimens. Eur J Surg Oncol 45(10):1895-1900. https://doi.org/10. 1016/j.ejso.2019.05.019

34. Klompmaker S, Peters NA, van Hilst J, Bassi C, Boggi U, Busch OR, Niesen W, Van Gulik TM, Javed AA, Kleeff J, Kawai M, Lesurtel M, Lombardo C, Moser AJ, Okada KI, Popescu I, Prasad R, Salvia R, Sauvanet A, Sturesson C, Weiss MJ, Zeh HJ, Zureikat AH, Yamaue H, Wolfgang CL, Hogg ME, Besselink MG, group EAD-Cs (2019) Outcomes and risk score for distal pancreatectomy with celiac axis resection (DP-CAR): an international multicenter analysis. Ann Surg Oncol 26(3):772-781. https://doi.org/10.1245/ s10434-018-07101-0

35. Klaiber U, Mihaljevic A, Hackert T (2019) Radical pancreatic cancer surgery-with arterial resection. Transl Gastroenterol Hepatol 4: 8. https://doi.org/10.21037/tgh.2019.01.07

36. Nakamura T, Hirano S, Noji T, Asano T, Okamura K, Tsuchikawa T, Murakami S, Kurashima Y, Ebihara Y, Nakanishi Y, Tanaka K, Shichinohe T (2016) Distal pancreatectomy with en bloc celiac axis resection (modified appleby procedure) for locally advanced pancreatic body cancer: a single-center review of 80 consecutive patients. Ann Surg Oncol 23(Suppl 5):969-975. https://doi.org/10. 1245/s10434-016-5493-8

37. Bachellier P, Addeo P, Faitot F, Nappo G, Dufour P (2020) Pancreatectomy with arterial resection for pancreatic adenocarcinoma: how can it be done safely and with which outcomes?: a single institution's experience with 118 patients. Ann Surg 271(5):932940. https://doi.org/10.1097/SLA.0000000000003010

38. Yoshiya S, Fukuzawa K, Inokuchi S, Kosai-Fujimoto Y, Sanefuji K, Iwaki K, Motohiro A, Itoh S, Harada N, Ikegami T, Yoshizumi T, Mori M (2020) Efficacy of neoadjuvant chemotherapy in distal pancreatectomy with en bloc celiac axis resection (DP-CAR) for locally advanced pancreatic cancer. J Gastrointest Surg 24(7): 1605-1611. https://doi.org/10.1007/s11605-019-04324-8

39. Delpero JR, Sauvanet A (2020) Vascular resection for pancreatic cancer: 2019 French recommendations based on a literature review from 2008 to 6-2019. Front Oncol 10:40. https://doi.org/10.3389/ fonc. 2020.00040

40. Kato H, Usui M, Isaji S, Nagakawa T, Wada K, Unno M, Nakao A, Miyakawa S, Ohta T (2013) Clinical features and treatment outcome of borderline resectable pancreatic head/body cancer: a multiinstitutional survey by the Japanese Society of Pancreatic Surgery. J Hepatobiliary Pancreat Sci 20(6):601-610. https://doi.org/10.1007/ s00534-013-0595-1

41. Gong H, Ma R, Gong J, Cai C, Song Z, Xu B (2016) Distal pancreatectomy with en bloc celiac Axis resection for locally advanced pancreatic cancer: a systematic review and meta-analysis. Medicine (Baltimore) 95(10):e3061. https://doi.org/10.1097/MD. 0000000000003061

42. Baumgartner JM, Krasinskas A, Daouadi M, Zureikat A, Marsh W, Lee K, Bartlett D, Moser AJ, Zeh HJ 3rd (2012) Distal pancreatectomy with en bloc celiac axis resection for locally advanced pancreatic adenocarcinoma following neoadjuvant therapy. J Gastrointest Surg 16(6):1152-1159. https://doi.org/10.1007/ s11605-012-1839-0

43. Ribas A, Wolchok JD (2018) Cancer immunotherapy using checkpoint blockade. Science 359(6382):1350-1355. https://doi.org/10. 1126/science.aar4060

44. Wang HC, Hung WC, Chen LT, Pan MR (2018) From friend to enemy: dissecting the functional alteration of immunoregulatory components during pancreatic tumorigenesis. Int J Mol Sci 19(11). https://doi.org/10.3390/ijms 19113584

45. Mota Reyes C, Teller S, Muckenhuber A, Konukiewitz B, Safak O, Weichert W, Friess H, Ceyhan GO, Demir IE (2020) Neoadjuvant therapy remodels the pancreatic cancer microenvironment via 
depletion of protumorigenic immune cells. Clin Cancer Res 26(1): 220-231. https://doi.org/10.1158/1078-0432.CCR-19-1864

46. Tang H, Qiao J, Fu YX (2016) Immunotherapy and tumor microenvironment. Cancer Lett 370(1):85-90. https://doi.org/10.1016/j. canlet.2015.10.009

47. Limagne E, Euvrard R, Thibaudin M, Rebe C, Derangere V, Chevriaux A, Boidot R, Vegran F, Bonnefoy N, Vincent J, Bengrine-Lefevre L, Ladoire S, Delmas D, Apetoh L, Ghiringhelli F (2016) Accumulation of MDSC and Th17 cells in patients with metastatic colorectal cancer predicts the efficacy of a FOLFOX-bevacizumab drug treatment regimen. Cancer Res 76(18):5241-5252. https://doi.org/10.1158/0008-5472.CAN-153164

48. Nevala-Plagemann C, Hidalgo M, Garrido-Laguna I (2020) From state-of-the-art treatments to novel therapies for advanced-stage pancreatic cancer. Nat Rev Clin Oncol 17(2):108-123. https://doi. org/10.1038/s41571-019-0281-6

49. Silva IP, Long GV (2017) Systemic therapy in advanced melanoma: integrating targeted therapy and immunotherapy into clinical practice. Curr Opin Oncol 29(6):484-492. https://doi.org/10.1097/ CCO.0000000000000405

50. Jones JO, Smyth EC (2020) Gastroesophageal cancer: navigating the immune and genetic terrain to improve clinical outcomes.
Cancer Treat Rev 84:101950. https://doi.org/10.1016/j.ctrv.2019. 101950

51. Taube JM, Anders RA, Young GD, Xu H, Sharma R, McMiller TL, Chen S, Klein AP, Pardoll DM, Topalian SL, Chen L (2012) Colocalization of inflammatory response with B7-h1 expression in human melanocytic lesions supports an adaptive resistance mechanism of immune escape. Sci Transl Med 4(127):127ra137. https://doi.org/10.1126/scitranslmed.3003689

52. Brooks J, Fleischmann-Mundt B, Woller N, Niemann J, Ribback S, Peters K, Demir IE, Armbrecht N, Ceyhan GO, Manns MP, Wirth TC, Kubicka S, Bernhardt G, Smyth MJ, Calvisi DF, Gürlevik E, Kühnel F (2018) Perioperative, spatiotemporally coordinated activation of $\mathrm{T}$ and $\mathrm{NK}$ cells prevents recurrence of pancreatic cancer. Cancer Res 78(2):475-488. https://doi.org/10.1158/0008-5472. can-17-2415

53. Liu J, Blake SJ, Yong MC, Harjunpaa H, Ngiow SF, Takeda K, Young A, O’Donnell JS, Allen S, Smyth MJ, Teng MW (2016) Improved efficacy of neoadjuvant compared to adjuvant immunotherapy to eradicate metastatic disease. Cancer Discov 6(12):13821399. https://doi.org/10.1158/2159-8290.CD-16-0577

Publisher's note Springer Nature remains neutral with regard to jurisdictional claims in published maps and institutional affiliations. 